Provided for non-commercial research and education use. Not for reproduction, distribution or commercial use.

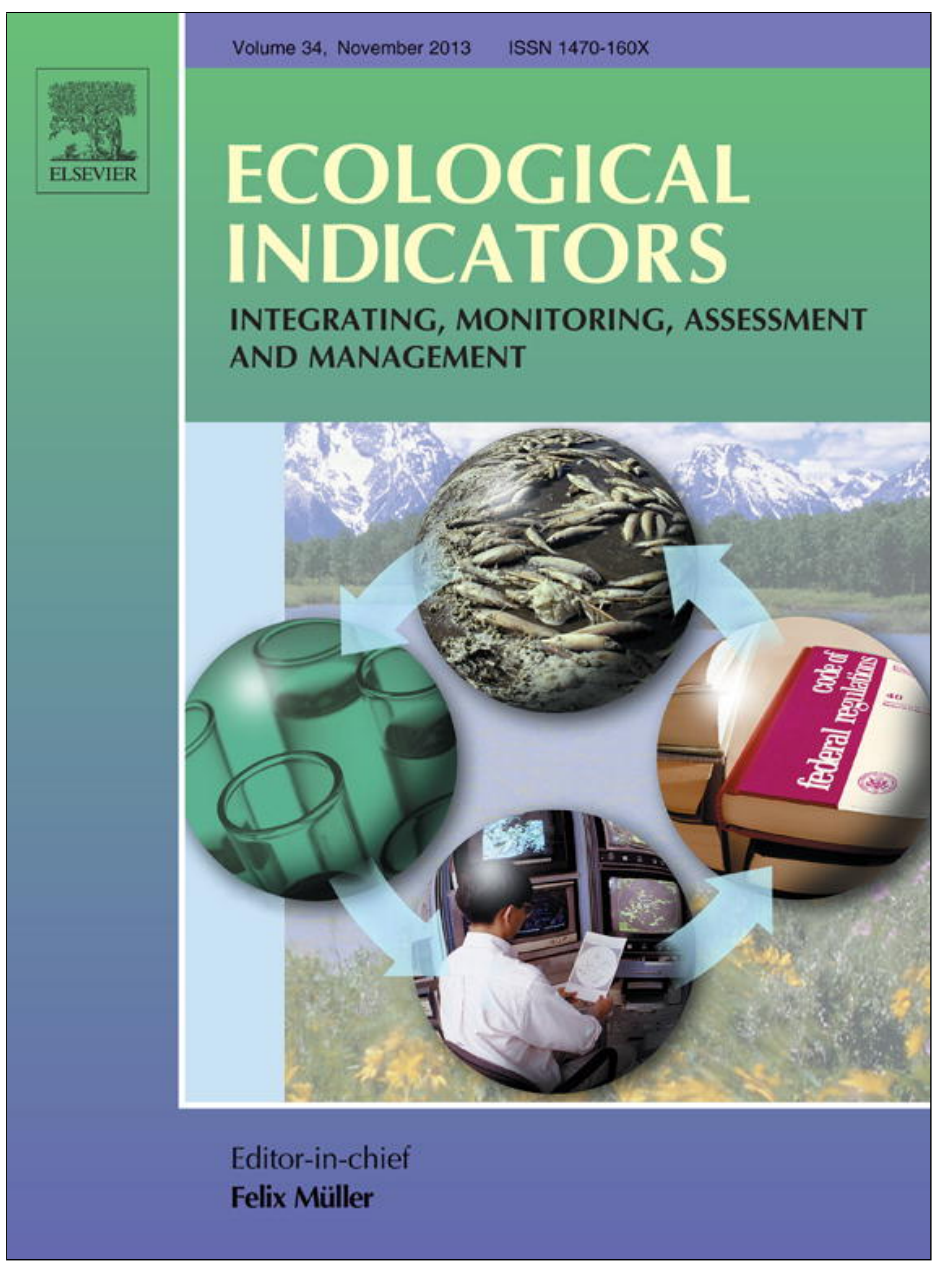

This article appeared in a journal published by Elsevier. The attached copy is furnished to the author for internal non-commercial research and education use, including for instruction at the authors institution and sharing with colleagues.

Other uses, including reproduction and distribution, or selling or licensing copies, or posting to personal, institutional or third party websites are prohibited.

In most cases authors are permitted to post their version of the article (e.g. in Word or Tex form) to their personal website or institutional repository. Authors requiring further information regarding Elsevier's archiving and manuscript policies are encouraged to visit:

http://www.elsevier.com/authorsrights 


\title{
Influences of the Grain-for-Green project on grain security in southern China
}

\author{
Qingshui $\mathrm{Lu}^{\mathrm{a}}$, Bo Xu ${ }^{\mathrm{b}}$, Fuyuan Liang ${ }^{\mathrm{c}, *}$, Zhiqiang Gao ${ }^{\mathrm{a}}$, Jicai Ning ${ }^{\mathrm{a}}$ \\ a Yantai Institute of Coastal Zone Researches, Chinese Academy of Sciences, Yantai 264003, China \\ ${ }^{\mathrm{b}}$ Department of Geography and Environmental Studies, California State University, San Bernardino, CA 92407, USA \\ ${ }^{c}$ Western Illinois University, Macomb, IL 61455, USA
}

\section{A R T I C L E I N F O}

\section{Article history:}

Received 14 November 2012

Received in revised form 20 June 2013

Accepted 27 June 2013

\section{Keywords:}

Soil erosion

RUSLE model

Grain security

Green-for-Grain

Southern China

\begin{abstract}
A B S T R A C T
Ensuring grain security has always been a top priority in China. As one of the major grain production areas in China, southern China is currently being criticized for the urban encroachment on prime agricultural land and decrease in grain production due to Grain-for-Green project. Based on the erosion pattern from the RUSLE model, spatial analysis is performed to analyze the possible loss of grain production if cropland under different degrees of soil erosion is exposed to the Grain-for-Green project. The projected total grain production on the basis of the 2000 grain production data in south China will decrease by $7.77 \%$ if cultivation is stopped on the cropland with high, very high, severe and very severe erosion, which, although not affects the grain security in southern China, would damage the grain security for the whole China. However, if all cropland on slopes above $25^{\circ}$ is converted to forest or grassland, grain production will decrease by $2.1 \%$. If all cropland covered with high, very high, severe and very severe erosion on slopes above $25^{\circ}$ is converted to forest or grassland, grain production will decrease by $0.91 \%$. Neither of the two measures will damage grain security in southern China, nor the whole China. So, the government should continue the Grain-for-Green project based on both slope and soil erosion degrees to ensure the grain security and reduce soil erosion at the same time.
\end{abstract}

Published by Elsevier Ltd.

\section{Introduction}

Soil erosion has become a serious threat to the agriculture in China. It is estimated that $18.5 \times 10^{8}$ tons of sediment are transported from land to the sea annually (Shi and Zhang, 2000). This huge amount of sediment flux leads to significant deposits in river channels, lakes, and reservoirs, which greatly decreases the capacity of flood storage (Pu et al., 1994; Yang et al., 2003; Liu et al., 2007). Soil erosion is also one of the major contributors to the reduction of soil fertility, and thus, the reduction of grain production (Qi et al., 2006; Wu et al., 2009; Su et al., 2010; Zhang et al., 2011; Otero et al., 2011).

The Grain-for-Green project was debuted in 1999 with the purpose of increasing forest cover and combating soil erosion on sloped cropland. In practice, governments designate certain quota of cropland in each province every year and farmers who agree to stop cultivating these lands would receive subsidies to cover their loss. In the long run, the Grain-for-Green project is able to significantly alleviate soil erosion and thus help restore the ecologic environment. However, ensuring grain production has always been given the top priority in China as China has the largest population in

\footnotetext{
* Corresponding author. Tel.: +1 309298 2956; fax: +1 3092983003.

E-mail address: F-Liang@Wiu.edu (F. Liang).
}

the World. The rapid urban sprawl in China further aggravates this problem due to the conversion of available cropland to urban area (Liu et al., 2005; Zhang and Duan, 2009). Obviously, a tradeoff has to be made to conserve the soil while maintaining enough grain production to feed the whole country. Influences of the Grain-forGreen project on grain production have been examined by Feng et al. (2005), Wang et al. (2007) and Xi et al. (2009). However, soil erosion was barely discussed in these studies though it is the most important factor to be considered in the Grain-for-Green project.

Southern China is the major grain production area and yields more than $65 \%$ of the total grain in China each year (State Statistic Bureau, 2000). This region is also nagged by the problems of soil erosion (Liu et al., 2009; Xu et al., 2010). This paper examines the spatial distribution of soil erosion in southern China and discusses the potential influences on the food security under the scenario of stopping cultivation on the cropland with high to very severe soil erosion. Results of this research should provide valuable insights for the government's further policy on the Grain-for-Green project.

\section{Study area and data sources}

\subsection{Study area}

Southern China, with 12 provinces, 1 autonomous region and 2 municipal cities (Fig. 1), has a total area of about $2.6 \times 10^{6} \mathrm{~km}^{2}$ 


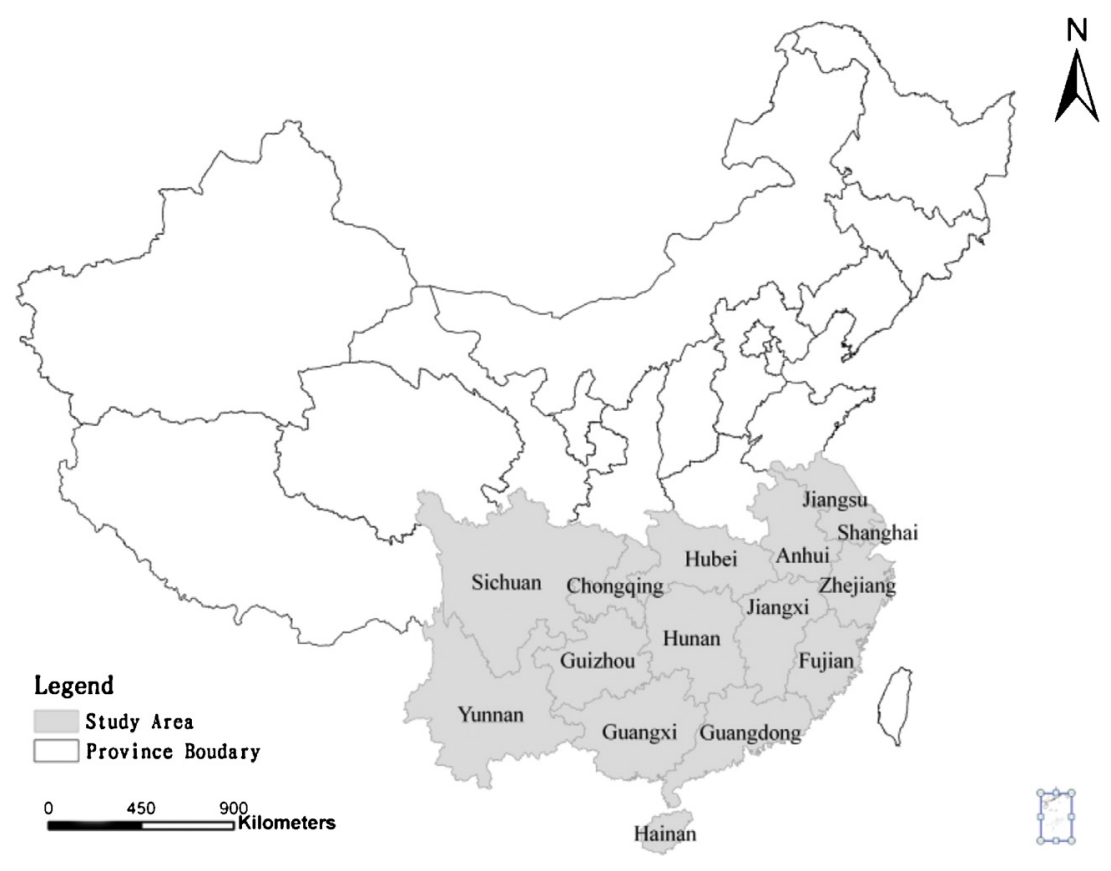

Fig. 1. Location of our study area.

and a total population of 0.72 billion in 2010 . The altitude in the study area varies from 0 to $6457 \mathrm{~m}$ above the mean sea level and the annual average rainfall is between 1000 and $2000 \mathrm{~mm}$. Major crop types planted in this area include rice, corn, and wheat. Red soil, latosol soil, latosolic red soil, yellow soil, and yellow-brown soil are the main types of soil in southern China (Chinese Soil Taxonomy Research Group, 1995).

\subsection{Data sources}

Two main datasets were used to estimate the potential threats to food security in southern China. The first one, the unit grain production at county levels in 2000, was derived from the local or state statistic yearbook (Local Statistic Bureau, 2000; State Statistic Bureau, 2000). The second dataset, the soil erosion modeling output, was calculated from the Revised Universal Soil Loss Equation (RUSLE). The data used for the input of the RUSLE model in our study area were the daily rainfall data, the land use/land cover map, the digital elevation model (DEM), the 1:1,000,000 map of Chinese soil, and the normalized difference vegetation index (NDVI) data. The daily rainfall data from 1980 to 2000 were obtained from the 320 weather observation stations in southern China recorded by the State Meteorological Bureau. The land use/land cover and Chinese soil data were downloaded from the Data center of Chinese Academy of Sciences (http://www.resdc.cn). The 30-m-posting DEM for our study area was acquired from U.S. Geological Survey (USGS) (www.usgs.gov). Spot NDVI data for the year 2000 was downloaded from the SPOT-Vegetation Program (www.spot_vegetation.com).

\section{Methodology}

\subsection{Soil erosion prediction}

Degree of soil erosion in our study area was estimated using the RUSLE model, which relates the rate of soil loss $(A)$ to the erosive power of the rain $(R)$, the soil erodibility $(K)$, the land slope and length $(L S)$, the degree of soil cove $(C)$, and conservation practices $(P)$, as in Eq. (1).

$A=R \bullet K \bullet L S \bullet C \bullet P$
The RUSLE model was developed by Renard et al. (1997) by incorporating new results of research, experiments, and data into its predecessor, the Universal Soil Loss Equation (USLE), which was published by Wischmeier and Smith (1978). In this study, an individual raster was prepared for each of the above five factors. The final rate of soil loss was then calculated with the spatial analysis functions in ArcGIS (ESRI, USA). These factors have been well defined in previous research (Wischmeier and Smith, 1978; Renard et al., 1997). However, for a specific area, different parameters should be used to compute the factors. The sections to follow describe the data and parameters utilized to calculate these factors based on recent research results in the study area.

\subsubsection{Erosive power of the rain $(R)$}

The $R$ factor represents the erosion potential of rainfall-runoff, which is directly related to erosion yield. This study used the equation developed by Zhang et al. (2002) to calculate $R$ (Eq. (2)).

$R=\alpha \sum_{j=1}^{k}\left(P_{j}\right)^{\beta}$

where $R$ is the half month rainfall erosivity factor in $\mathrm{mm} \mathrm{ha}^{-1} \mathrm{~h}^{-1}$ year $^{-1}, K$ is the total number of days in the corresponding half month, $P_{j}$ is the erosive rainfall for day $j$, and $\alpha$ and $\beta$ are model parameters.

The daily rainfall data of the period from 1980 to 2000 in each month was divided into two sections by its fifteenth day and thus there were 24 sections for one year. $M$ was then computed for each of these 24 sections. For a specific section, the total number of days $(K)$ was calculated first. For the $j$ th day in this section, $P_{j}$ was the total rainfall if it was higher than $12 \mathrm{~mm}$ (Xie et al., 2000). Otherwise, $P_{j}$ would be 0 and was not considered in the calculation. Model parameters $\alpha$ and $\beta$ were calculated according to Eq. (3).

$\beta=0.8363+\frac{18.144}{P_{d 12}}+\frac{24.455}{P_{y 12}}, \quad \alpha=21.586 \beta^{-7.1891}$

where $P_{d 12}$ and $P_{y 12}$ are the average daily and annual rainfall of the days with a total rainfall more than $12 \mathrm{~mm}$, respectively. The final $R$ values were calculated for each of the weather observation stations 

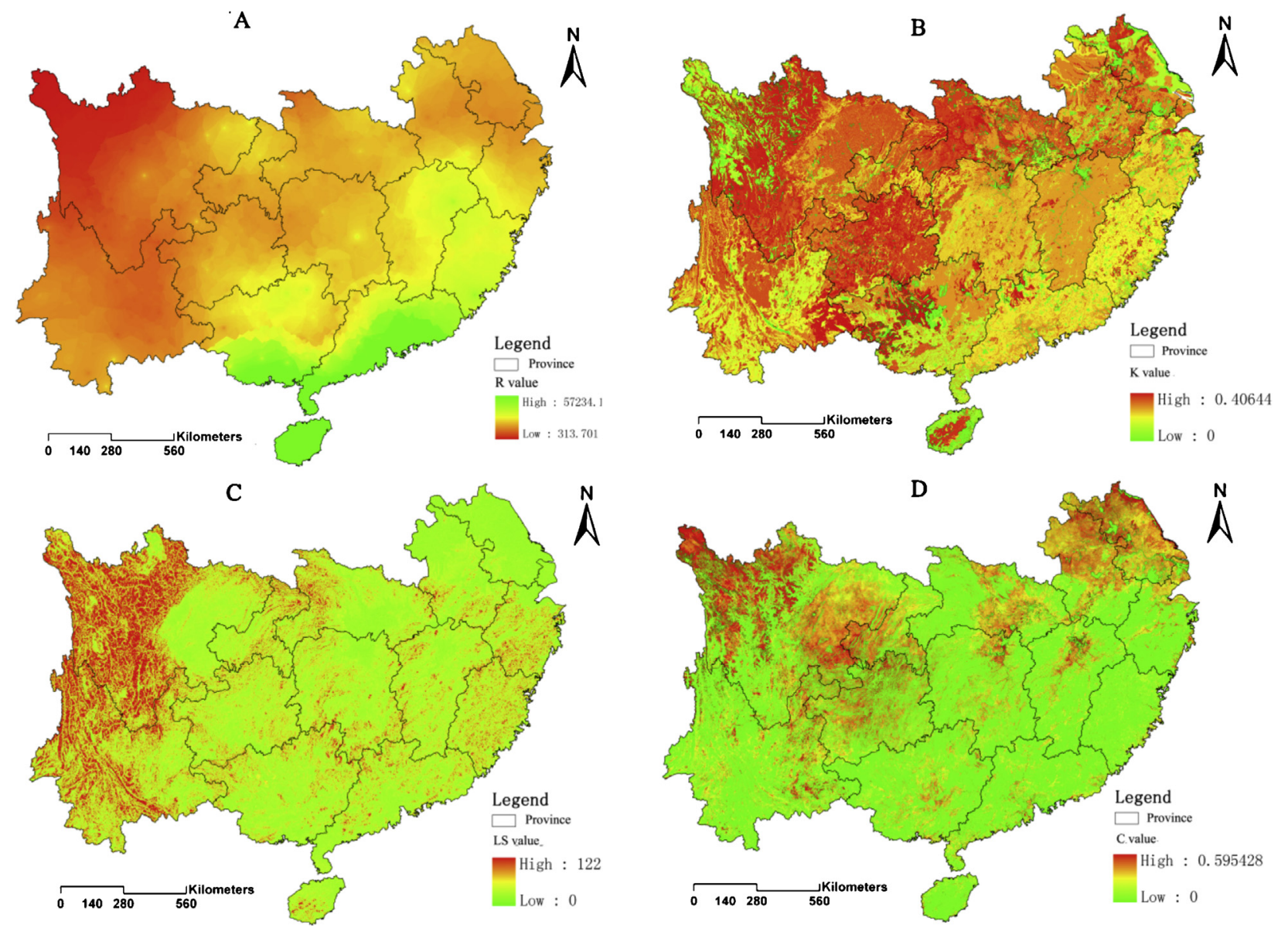

Fig. 2. Distribution of factors of RUSLE (A: $R$ values, B: $K$ values, C: $L S$ values, D: $C$ values).

and a map of the $R$ values (Fig. 2A) was prepared for our study area using the Spline interpolation method in ArcGIS.

\subsubsection{Soil erodibility factor $(K)$}

This factor mainly measures the influence of soil texture and other soil characteristics on soil loss. It was calculated with Eq. (4).

$K=7.954 \times\left\{0.0017+0.0494 \times \exp \left[-\frac{1}{2}\left(\frac{\log \left(D_{g}\right)+1.675}{0.6986}\right)^{2}\right]\right\}_{(4)}$

where $D_{g}$ represents the average soil particle size, which was acquired from the 1:1,000,000 Chinese Soil Database. Final results of the $K$ factor were shown in Fig. 2 B.

\subsubsection{Length-slope factor ( $L S)$}

The $L S$ factor implies the topographic influence on the soil erosion as soil loss tends to increase with increasing slope steepness and length. The slope steepness and slope length were first calculated from the ASTER DEM data from The National Aeronautics and Space Administration (NASA). Then the $L S$ factor was computed with Eqs. (5) or (6) which were proposed by Remortel et al. (2001) under different scenarios.

If the slope $(\theta)$ is less than $5^{\circ}$, Eq. (5) is adopted.

$L S=\left(\frac{\lambda}{22.13}\right)^{m}(10.8 \sin \theta+0.03)$
If $\theta$ is no less than $5^{\circ}$, Eq. (6) is used.

$$
L S=\left(\frac{\lambda}{22.13}\right)^{m}(16.8 \sin \theta-0.96)
$$

where $\lambda$ is the slope length and $m$ is the slope exponent. One should refer to Remortel et al. (2001) for detailed values of $m$. Final output values of the $L S$ factor were mapped in Fig. 2C.

3.1.4. Cover and management factor $(C)$

Amount of soil erosion is also affected by vegetation cover and different methods of crop management. In this study, the factor $C$ was derived using Eq. (7) (Liu et al., 2010).

$C=C_{c} \times C_{s}$

where $C_{c}$ and $C_{s}$ are the canopy and surface cover factors, respectively. For cropland and grassland, the $C_{c}$ factor was calculated as follows (Eq. (8)):

$C_{c}=1-\left(0.01 V_{c}+0.0859\right) e^{-0.0033 h}$

For forestry, the $C_{c}$ factor was calculated with Eq. (9):

$C_{c}=0.5262 * e^{-0.05 V_{c}}$

The $C_{S}$ factor was computed based on the following Eq. (10):

$C_{S}=1.029 e^{-0.0235 V_{c}}$

where $V_{c}$ is the vegetation coverage percentage (\%), and $h$ is the canopy height $(\mathrm{cm}) . V_{c}$ was acquired from Eq. (11) (Zhang et al., 2011):

$V_{c}=\frac{\mathrm{NDVI}-\mathrm{NDVI}_{\min }}{\mathrm{NDVI}_{\max }-\mathrm{NDVI}_{\min }}$ 
Table 1

$P$ values for different types of land use/land cover.

\begin{tabular}{lllllll}
\hline LUCC & Paddy field & Dry farm & Forest & Grassland & Water and swamp & City and village \\
\hline$P$ value & 0.01 & $0.5-0.9$ & 1 & 1 & 0 & 0
\end{tabular}

where NDVI is the NDVI for a specific land use/land cover patch, and $\mathrm{NDVI}_{\text {min }}$ and $\mathrm{NDVI}_{\max }$ are the minimum and maximum NDVI values for the same patch. Final results of the $C$ factor were shown in Fig. 2D.

\subsubsection{Conversation practice factor $(P)$}

Soil erosion rate is also related to supporting practices such as tillage and crop rotation. Terraces are usually built for sloping cropland while ridges for paddy rice fields. By contrast, conservation practices are normally not available for forestry and grassland. Therefore, different $P$ values were assigned for different land use/land cover categories (Table 1) as recommended by Wischmeier and Smith (1978), Renard et al. (1997) and Xu et al. (2011).

\subsection{Spatial analysis}

Soil erosion potential was calculated by overlaying the aforementioned five factors in ArcGIS. The output values of average annual soil loss were grouped into seven degrees following the criteria proposed by the Ministry of Water Resources of China (2008). Spatial analysis was then implemented in ArcGIS to reveal the potential decrease in grain production if farming was discontinued in areas experiencing specific degree of soil erosion based on the soil loss output and the unit grain production data.

\section{Results and analysis}

\subsection{Soil erosion in southern China}

Fig. 3 shows the final predicted soil erosion rate of southern China. Generally speaking, east southern China shows lower soil erosion rate than west southern China. The Middle and Lower Yangtze River Plain, the China paddy rice field zone, experiences no obvious soil erosion. The vast areas south to the middle and lower Yangtze River plain have slight soil erosion. By contrast, the high-altitude areas in Yunnan-Guizhou plateau, the Chongqing municipal city, and the central Sichuan province experience moderate, high, very high, and occasionally severe soil erosion. This predicting soil erosion rates in southern China agree well with the general descriptions from the Ministry of Water Resources of China (2008). The predicted results were also compared with the results with ${ }^{137} \mathrm{Cs}$ techniques in Puding county, Guizhou Province. Our predicted result in Puding county is $20 \mathrm{t} / \mathrm{hm}^{-2}$ year $^{-1}$ and it fits well with results with ${ }^{137} \mathrm{Cs}$ techniques (Bai, 2011).

\subsection{Cropland, grain production, and soil erosion}

Table 2 summarizes the percentage of cropland and grain production in each class of soil erosion. Most of the cropland (89.49\%) in southern China experiences no obvious or moderate soil loss. Percentages of cropland that falls into slight, high, very high, and severe soil erosion classes are $1.25 \%, 7.77 \%, 1.38 \%$, and $0.2 \%$, respectively. Only negligible percentage of cropland is exposed to sever soil erosion. Grain production in the cropland shows similar pattern, with about $92.46 \%$ of grain produced from the cropland with no obvious and moderate soil erosion. Cropland that falls into other classes of soil erosion only yields less than $8 \%$ of the grain in southern China, among which the grain production from cropland with severe soil erosion is also negligible. The percentages of cropland and grain production decrease as the land slope increases (Table 3 ).

\subsection{Grain security and Grain-for-Green project}

China government issued the China Grain Problem white book in 1996. In this book, it is recommended that the baseline of grain self-sufficiency rate should be no less than $95 \%$. According to previous studies, the annual minimum grain consumption in China is

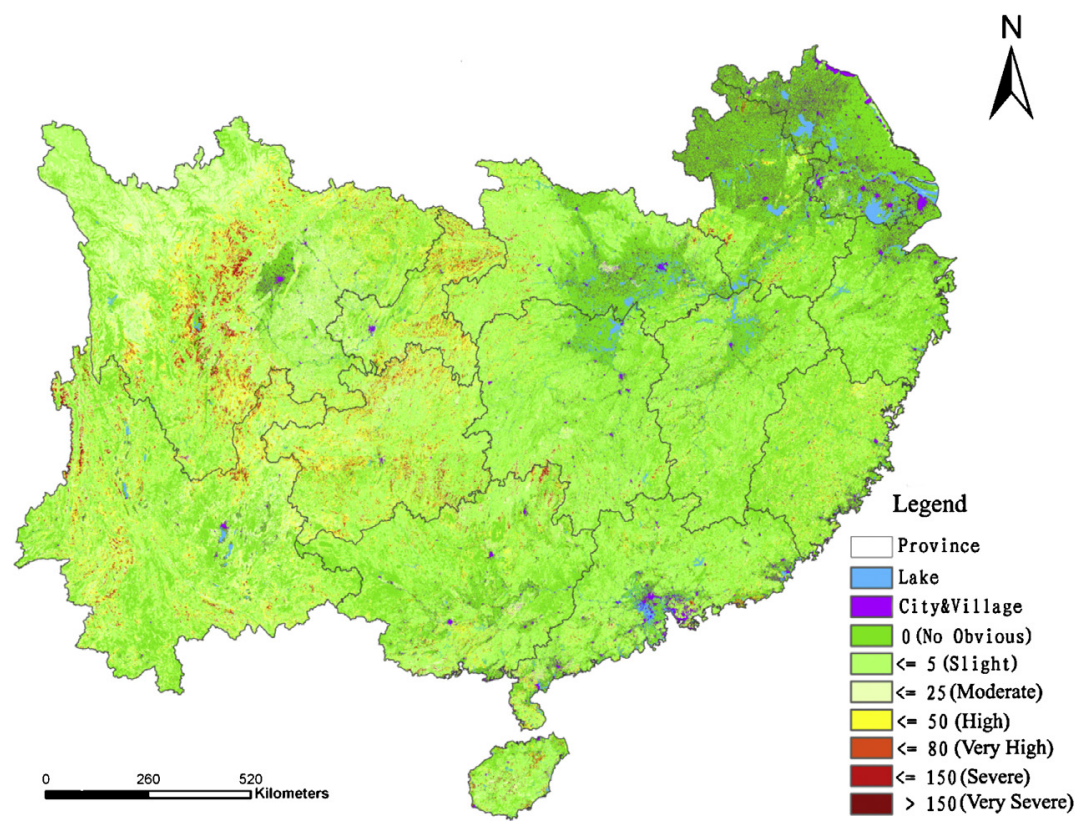

Fig. 3. Predicted soil erosion rate in southern China based on the RULSE. 
Table 2

Cropland and grain production in each erosion class in 2000.

\begin{tabular}{|c|c|c|c|c|c|c|c|}
\hline Erosion classes & No obvious erosion & Slight erosion & Moderate erosion & High erosion & Very high erosion & Severe erosion & Very severe erosion \\
\hline Cropland (\%) & 66.15 & 1.25 & 23.23 & 7.77 & 1.38 & 0.20 & 0.00 \\
\hline Cropland $\left(10^{6} \mathrm{ha}\right)$ & 50.56 & 0.95 & 17.75 & 5.94 & 1.06 & 0.15 & 0.00 \\
\hline Grain production (\%) & 68.02 & 0.96 & 24.44 & 5.62 & 0.83 & 0.12 & 0.00 \\
\hline Grain production $\left(10^{6} \mathrm{t}\right)$ & 216.49 & 3.07 & 77.79 & 17.89 & 2.65 & 0.38 & 0.00 \\
\hline
\end{tabular}

Table 3

Cropland and grain production for different slopes in southern China in 2000.

\begin{tabular}{|c|c|c|c|c|c|c|c|}
\hline Slopes (degree) & $0-5$ & $5-10$ & $10-15$ & $15-20$ & $20-25$ & $>25$ & Total \\
\hline Cropland (\%) & 64.7 & 13.5 & 8.9 & 6.0 & 3.6 & 3.2 & 100 \\
\hline Cropland $\left(10^{6} \mathrm{ha}\right)$ & 49.48 & 10.33 & 6.82 & 4.59 & 2.73 & 2.47 & 76.42 \\
\hline Grain production (\%) & 74.11 & 15.9 & 0.03 & 5.15 & 2.71 & 2.1 & 100 \\
\hline Grain production $\left(10^{6} \mathrm{t}\right)$ & 235.88 & 50.61 & 0.08 & 16.39 & 8.62 & 6.7 & 318.3 \\
\hline
\end{tabular}

Table 4

Grain consumption, production and baseline of grain security in 2000 . $^{*}$

\begin{tabular}{llllcr}
\hline Region & Population (billion) & Consumption $\left(10^{6} \mathrm{t}\right)$ & Production $\left(10^{6} \mathrm{t}\right)$ & Self-sufficiency percentage $(\%)$ & Baseline $\left(10^{6} \mathrm{t}\right)$ \\
\hline China & 1.26 & 503.6 & 494.5 & 98.2 & 478.42 \\
South & 0.72 & 286.8 & 318.3 & 110.1 & -9.1 \\
North & 0.54 & 216.9 & 176.2 & 81.5 & +31.5 \\
\hline
\end{tabular}

"Source: statistical yearbook of China (State Statistic Bureau, 2000).

Table 5

Cropland loss and grain self-sufficiency.

\begin{tabular}{|c|c|c|c|c|c|c|}
\hline \multirow[t]{2}{*}{ Converted cropland } & \multicolumn{2}{|c|}{ Loss of cropland in southern China } & \multicolumn{2}{|c|}{ Loss of grain production in southern China } & \multicolumn{2}{|c|}{ Self-sufficiency percentage } \\
\hline & Area $\left(10^{6} \mathrm{ha}\right)$ & $\begin{array}{l}\text { Percentage in } \\
\text { southern china (\%) }\end{array}$ & Production $\left(10^{6} \mathrm{t}\right)$ & Percentage in southern China (\%) & Southern China (\%) & China (\%) \\
\hline On slope less than $25^{\circ}$ & 2.47 & 3.2 & 6.7 & 2.1 & 100 & 96.7 \\
\hline $\begin{array}{l}\text { High to very severe erosion } \\
\text { on slopes no less than } 25^{\circ}\end{array}$ & 1.1 & 1.4 & 2.9 & 0.91 & 100 & 97.6 \\
\hline High to very severe erosion & 7.2 & 8 & 20.9 & 7.77 & 100 & 94 \\
\hline
\end{tabular}

$400 \mathrm{~kg}$ per capita (Chinese Academy of Agricultural Sciences, 1986; Chang, 2005; He and Yang, 2008). In 2000, the total grain consumption in China is $503.6 \times 10^{6} \mathrm{t}$ and the actual grain production is $494.5 \times 10^{6} \mathrm{t}$, with a real self-sufficiency percentage of $98.2 \%$ which is higher than the baseline of self-sufficiency percentage (Table 4). By examining northern China and southern China, respectively, it is clear that this high self-sufficiency percentage is attributed to the surplus of grain in southern China, which has always been the China barn during the past centuries.

The Grain-for-Green project attempts to stop cultivation and resume forest cover on certain cropland. When this ambitious project completes, more than 13 million hectares of cropland will be converted into forest or pasture across China. Among the land that would be converted, 6 million hectares is cultivated land that has a slope of at least $25^{\circ}$ (Uchida et al., 2005). Table 5 describes the estimated loss of cropland in southern China, the resulting loss of grain production and grain self-sufficiency percentage. As shown in this research, about 2.47 million out of the 6 million hectares of cultivated land is located in southern China. By the time when all the qualified cropland is converted into forest or pasture, there will be $2.1 \%$ of loss in the grain production in southern China (Table 5). The grain self-sufficiency percentage will still be $100 \%$ in southern China, and will decrease to $96.7 \%$ for the whole China if we assume the grain production in northern China is constant during this period. That means the projected grain production after the implementation of Grain-for-Green project on the cropland with a slope of $25^{\circ}$ and above in southern China will remain higher than the baseline of self-sufficiency for southern China, as well as for the whole China. However, whether this will actually affect the grain security for the whole China depends on the situations of Grain-for-Green project in northern China.

The initial purpose of the Grain-for-Green project is to reduce soil erosion by shifting sloped cropland into forest or pasture. It is worthy to note that not all of the cropland with a land slope at least $25^{\circ}$ is exposed to serious soil erosion (Table 5). Among the $3.2 \%$ $\left(2.47 \times 10^{6} \mathrm{ha}\right)$ cropland that has a slope at least $25^{\circ}$ in southern China, only $1.4 \%$ percent $\left(1.1 \times 10^{6} \mathrm{ha}\right)$ is experiencing high to very severe soil erosion. If this $1.4 \%$ cropland is converted into forest or pasture, grain production will only decrease by $0.91 \%\left(2.9 \times 10^{6} \mathrm{t}\right)$ which will not influence grain security in southern China $(100 \%$ of self-sufficiency percentage) and the grain security in the whole China $(97.6 \%$ of self-sufficiency percentage). Thus, it is more valuable and rational to convert cropland that is suffering high to very severe soil erosion and has a slope at least $25^{\circ}$ to forest or pasture.

Table 6

Grain consumption, production and baseline of grain security in 2005

\begin{tabular}{llllrr}
\hline Region & Population (billion) & Consumption $\left(10^{6} \mathrm{t}\right)$ & Production $\left(10^{6} \mathrm{t}\right)$ & Self-sufficiency percentage $(\%)$ & Baseline $\left(10^{6}\right)$ \\
\hline China & 1.3 & 519.95 & 469.47 & 90.3 & 493.95 \\
South & 0.75 & 300.16 & 235.8 & 78.6 & 285.15 \\
North & 0.55 & 219.78 & 233.67 & 106.5 & -64.36 \\
\hline
\end{tabular}

" Source: statistical yearbook of China (State Statistic Bureau, 2005). 
Meanwhile, high to very severe soil erosion does exist for the cropland with slopes less than $25^{\circ}$. If all cropland that is suffering high to very severe soil erosion (including all slopes) are converted into forest or pasture, total loss in grain production in southern china will be $20.9 \times 10^{6} \mathrm{t}(7.77 \%)$. The barn will lose its historic function and China self-sufficiency rate will decrease to $94 \%$. Although this will not threat the grain security in southern China $(110.1 \%$ of self-sufficiency percentage in southern China), it will damage the grain security in the whole China.

\section{Discussion and conclusions}

Through spatial analysis of the soil erosion and the unit grain production in southern China, we find that most of the cropland $(89.49 \%)$ in this area experiences no obvious or moderate soil loss, and only negligible percentage of cropland is exposed to sever soil erosion. About $74.11 \%$ grain is produced in cropland with slope below $5^{\circ}$. If all cropland with high, very high, severe and very severe erosion is converted to forest or grassland, the selfsufficiency percentage is still above the baseline of grain security in southern China, but will damage the grain security for the whole China if the grain production in northern China is assumed to be constant.

If all cropland with a slope of $25^{\circ}$ and above is converted to forest or grassland, grain production will decrease by $2.1 \%$ in southern China. If all cropland covered with high, very high, severe and very severe erosion and with a slope of $25^{\circ}$ and above is converted to forest or grassland, grain production will decrease by $0.91 \%$. Neither will damage the grain security in southern China, nor the whole China. Therefore, it is possible to execute Grain-for-Green project on cropland with a slope of $25^{\circ}$ and above, especially on the cropland with a slope of $25^{\circ}$ and above and under high, very high, severe and very severe erosion classes.

However, the grain production actually decreased from 2000 to 2005 in southern China and contributed to the low self-sufficiency rate for the whole China (Table 6). The self-sufficiency rate was even lower in southern China itself (78.6\%). During this period, much more cropland was lost due to urban encroachment (692,858 ha) than the Grain-for-Green project (71,225 ha). It is clear that the grain security problem is mainly caused by urban sprawl rather than the Grain-for-Green project during this period. Furthermore, the cropland occupied by urbanization is mostly flat and with good productivity, while only the cropland with high slope and prone to erosion is converted to forest or pasture in the Grain-forGreen project. The latter is more environment-friendly and has less influence on grain production. Therefore, the government should continue to implement the Grain-for-Green project in the future. At the same time, more agriculture-friendly policies should be proposed to boost grain productivity to offset the negative effects of urban sprawl.

Most of the cropland with high to very severe erosive land in southern China is distributed in western part of southern China and usually is low-yielding. There are less big cities and industrial cores in this region and the living standard is low. The farmers who are willing to stop cultivation on their sloped or erosive cropland will receive subsidy from government for limited time period. They may re-cultivate the retired cropland once the subsidy is no more available (Ye et al., 2003; Cao et al., 2009). This will, again, lead to a gradual increase in soil erosion.

Many erosion control measures could be used to reduce soil erosion. However, the cost is very high (Jin and Englande, 2009) and subsidies from government might be a necessity. It seems that migration might be a wise policy to significantly reduce soil erosion and protect environment in these areas. As of 2010, there is about $50 \%$ of population living in urban area (State Statistic Bureau, 2010) and there is still a high demand of labors in very industrialized cities in east coast of China. If Chinese government encourages people who live in areas that are susceptible to high to very severe soil erosion to migrate to eastern urban areas, it will significantly help protect soil from erosion in these areas and also help mitigate the labor shortage problems in the urbanized areas. The data in 2000 were used in this study, though about ten years ago, which are the most detailed and accurate data available by now, and the results based on the data can provide the government valuable information and support for the impletion of the Grain-for-Green project. Chinese government should consider both slope and soil erosion degree when implementing Grain-for-Green project to ensure grain security and improve soil quality at the same time.

\section{Acknowledgements}

Land use/land cover data in 2000 was from Professor Liu Jiyuan, rainfall data from State Meteorological Bureau, 1:1 million map from data center of Chinese Academy of Sciences, Dem from USGS. This study was supported by the National Natural Science Foundation of China (41071278 and 41171334) Talent fund of Yantai Institute of Coastal Zone Research, Ecological Innovation \& Breeding Project (Y254021031 and 355031061), the Science and Technology Project of Yantai (2012132). Thanks them all. 


\section{Appendix A. Appendix cross table of grain production and cropland for different soil erosion classes and different slope range.}

\begin{tabular}{|c|c|c|c|c|c|c|c|c|c|}
\hline & & & \multicolumn{7}{|l|}{ Soil erosion classes } \\
\hline & & & No obvious erosion & Slight erosion & Moderate erosion & High erosion & Very high erosion & Severe erosion & Very severe erosion \\
\hline \multirow[t]{12}{*}{ Slope } & \multirow[t]{2}{*}{$0-5$} & Grain production & $184,965,000$ & 1507.3 & $43,333.8$ & 5697.2 & 354.7 & 21.1 & 0.3 \\
\hline & & Cropland area & $40,871,889$ & 350,840 & $7,027,163$ & $1,130,190$ & 89,949 & 6579 & 95 \\
\hline & \multirow[t]{2}{*}{$\leq 10$} & Grain production & $22,705.6$ & 1086.7 & $22,507.6$ & 3961.1 & 325.4 & 20.8 & 0.2 \\
\hline & & Cropland area & $4,789,118$ & 277,504 & $4,206,005$ & 959,718 & 93,987 & 6511 & 41 \\
\hline & \multirow[t]{2}{*}{$\leq 15$} & Grain production & 10.0 & 35.0 & 20.3 & 13.4 & 3.8 & 0.8 & 0.00 \\
\hline & & Cropland area & $2,426,877$ & 150,527 & $2,806,260$ & $1,224,550$ & 190,003 & 18,687 & 105 \\
\hline & \multirow[t]{2}{*}{$\leq 20$} & Grain production & 5008.1 & 229.1 & 6524.7 & 3809.4 & 725.0 & 91.2 & 0.9 \\
\hline & & Cropland area & $1,324,551$ & 83,290 & $1,801,848$ & $1,115,479$ & 237,172 & 31,397 & 249 \\
\hline & \multirow[t]{2}{*}{$\leq 25$} & Grain production & 2298.3 & 116.1 & 3199.6 & 2353.6 & 558.7 & 88.0 & 1.0 \\
\hline & & Cropland area & 659,445 & 49,341 & $1,036,655$ & 756,921 & 193,137 & 31,319 & 325 \\
\hline & \multirow[t]{2}{*}{$>25$} & Grain production & 1500.9 & 91.0 & 2207.9 & 2056.2 & 679.1 & 157.3 & 4.3 \\
\hline & & Cropland area & 486,273 & 46,927 & 873,533 & 753,662 & 252,854 & 58,159 & 1379 \\
\hline
\end{tabular}

Note: Unit of grain production is $10^{3} \mathrm{t}$ and unit of cropland area is ha.

\section{References}

Bai, X.Y, 2011. Assessment of sediment and erosion rates by using thecaesium137 technique in a Chinese polygonal karst depression. Environ. Earth Sci. 64, 2151-2158

Cao, S.X., Xu, C.G., Chen, L., Wang, X.Q., 2009. Attitudes of farmers in China's northern Shaanxi Province towards the land-use changes required under the Grain-forGreen project, and implications for the project's success. Land Use Policy 26 (4) 1182-1194.

Chang, P.F., 2005. A time series forecasting of food-grain consumption per capita in China. J. Shanxi Agric. Univ. 2005 (1), 87-91 (in Chinese with English abstract).

Chinese Academy of Agricultural Sciences, 1986. 400 kilograms of grain per capita are essential to China. Sci. Agric. Sinica 19 (5), 1-7 (in Chinese with English abstract).

Chinese Soil Taxonomy Research Group, 1995. Chinese Soil Taxonomy Research Group. Institute of Soil Science. Academia Sinica and Cooperative Research Group on Chinese Soil Taxonomy. Chinese Soil Taxonomy (Revised Proposal). China Agricultural Science and Technology Press, Beijing.

Feng, Z.M., Yang, Y.Z., Zhang, Y.Q., Zhang, P.T., Li, Y.Q., 2005. Grain-for-Green policy and its impacts on grain supply in West China. Land Use Policy 22, 301-312.

He, Y.M., Yang, Z.S., 2008. Analysis of regional per capita food demand based on food security. Chin. Bus. 2008 (7), 6-8 (in Chinese with English abstract).

Jin, G., Englande, A.J., 2009. A field study on cost-effectiveness of five erosion control measures. Manag. Envion. Qual. (Manag. Environ. Qual. Int. J.) 20 (1), 6-20.

Liu, A.X., Wang, J., Liu, Z.J., 2009. Remote sensing quantitative monitoring of soil erosion in three Gorges reservoir area: a GIS/RUSLE-based research. J. Nat. Disasters 18 (4), 25-30 (in Chinese with English abstract).

Liu, B.Y., Bi, X.G., Fu, S.H., et al., 2010. Beijing Soil Loss Formula. Science Press, Beijing (in Chinese).

Liu, J.P., Xu, K.H., Li, A.C., Milliman, J.D., Velozzi, D.M., Xiao, S.B., Yang, Z.S., 2007. Flux and fate of Yangtze River sediment delivered to the East China Sea. Geomorphology $85(3 / 4), 08-224$.

Liu Jiyuan, Tian Hanqin, Liu Mingliang, Zhuang Dafang, Melillo, Jerry M., Zhang Zengxiang, 2005. China's changing landscape during the 1990: large-scale land transformations estimated with satellite data. Geogr. Res. Lett. 32, 1-5.

Local Statistic Bureau, 2000. Local Statistic Yearbook. China Statistic Press, Beijing.

Ministry of Water Resources of China, 2008. Standards for Classification and Gradation of Soil Erosion. China Waterpower Press, Beijing.

Otero, J.D., Figueroa, A., Munoz, F.A., Pena, M.R., 2011. Loss of soil and nutrients by surface runoff in two agro-ecosystems within an Andean paramo area. Ecol. Eng. 37, 2035-2043.

Pu, P.M., Cai, S.M., Zhu, H.H., et al., 1994. Project of Three Gorges Reservoir and Lakes in Middle and Low Reaches of Yangtz River. Science Press, Beijing (in Chinese).

Qi, Y.Q., Zhang, X.B., He, W.X., Wen, A.B., Fu, J.X., 2006. A study on soil erosion induced sediment yield by reservoir and pond deposits dating with ${ }^{137} \mathrm{Cs}$ in small catchments of the hilly Sichuan Basin and the three Gorges region. Geogr. Res. 25 (4), 641-648 (in Chinese with English abstract).

Remortel, V.R., Hamilton, M., Hickey, R., 2001. Estimating the LS factor for RUSLE through iterative slope length processing of DEM elevation data. Cartogr J 30 (1), 27-35.
Renard, K.G., Foser, G.R., Weesies, G.A., 1997. Predicting soil erosion by water: a guide to conservation planning with the revised universal soil loss equation (RUSLE) In: Agriculture Handbook No. 703. U.S. Department of Agriculture, Washington, DC.

Shi Changxing, Zhang Dian, 2000. Analysis of impacts of sedimentation on flooding disasters in China. Acta Geogr. Sinica 55 (5), 627-636.

State Statistic Bureau, 2000. Statistic Yearbook. China Statistic Press, Beijing. State Statistic Bureau, 2005. Statistic Yearbook. China Statistic Press, Beijing.

State Statistic Bureau, 2010. Statistic Yearbook. China Statistic Press, Beijing.

Su Zhengan, Zhang Jianhui, NieXiaojun, 2010. Effect of soil erosion on soil properties and crop yields on slopes in the Sichuan Basin, China. Pedosphere 20 (6), 736-746.

Uchida, E., Xu, J.T., Rozelle, S., 2005. Grain for Green: Cost-effectiveness and Sustainability of China's Conservation Set aside Program. Land Economics. 81 (2), 247-264.

Wang, X.H., Lu, C.H., Fang, J.F., Shen, Y.C., 2007. Implications for development of Grain-for-Green policy based on cropland suitability evaluation in desertification-affected north China. Land Use Policy 24 417-424.

Wischmeier, W.H., Smith, D.D., 1978. Predicting rainfall erosion losses: a guide to conservation planning. In: Agriculture Handbook No. 537. U.S. Department of Agriculture.

Wu, N., Gao, J.X., Sudebilige, Luo, Z.L., Driss, E., Guillemo, E.M., 2009. Evaluation on ecosystem service of avoided reservoir sedimentation and its economic value under different land use/cover scenarios. Acta Ecol. Sinica 29 (11), 5912-5922 (in Chinese with English abstract).

$\mathrm{Xi}$, J., Cao, M.M., Chen, H., 2009. Impacts of grain for green program on landuse behavior of peasant households. Bull. Soil Water Conserv. 29 (3), 5-9.

Xie, Y., Liu, B.Y., Zhang, W.B., 2000. Study on standard of erosive rainfall. J. Soil Water Conserv. 14 (4), 6-11 (in Chinese with English abstract).

Xu, Y.L., Wu, G.H., Ma, X.M., 2010. Study on estimation of the amount of soil erosion based on GIS and RS - taking the Sun Mountain Area of Chengjiang County as an example. Remote Sens. Inf. 2010 (3), 65-70 (in Chinese with English abstract).

Xu, Y.Q., Luo, D., Peng, J., 2011. Land use change and soil erosion in the Maotiao River watershed of Guizhou Province. J. Geogr. Sci. 21 (6), 1138-1152.

Yang, S.L., Belkin, I.M., Belkina, A.I., Zhao, Q.Y., Zhu, J.P., Ding, X., 2003. Delta response to decline in the sediment supply from the Yangtze River: evidence of the recent four decades and expectations for the next half-century. Estuar. Coast. Shelf Sci. 57, 689-699.

Ye, Y.Q., Chen, G.J., Fan, H., 2003. Impacts of the Grain-for-Green project on rural communities in the Upper Min River Basin, Sichuan, China. Mt. Res. Dev. 23 (4), 345-352.

Zhang, M.L., Yang, H., Zou, J., Xu, L., Sui, Z.L., 2011. Effects of soil erosion on soil quality in the rocky mountain areas of Northern China. J. Soil Water Conserv. 2011 (2), 218-221 (in Chinese with English abstract).

Zhang, W.B., Xie, Y., Liu, B.Y., 2002. Rainfall erosivity estimation using daily rainfall amounts. Sci. Geogr. Sinica 22 (6), 705-711 (in Chinese with English abstract).

Zhang, Z.B., Duan, Z.Y., 2009. Where is the way for increasing the ability of grain security in China. Bull. Chin. Acad. Sci. 2009 (6), 610-616 (in Chinese with English abstract). 